\title{
Testicular Blood Flow and Plasma Concentrations of Testosterone and Total Estrogen in the Stallion after the Administration of Human Chorionic Gonadotropin
}

\author{
Heinrich BOLLWEIN ${ }^{1)}$, Johann Joachim SCHULZE ${ }^{1,2)}$, Akio MIYAMOTO ${ }^{3)}$ and Harald SIEME ${ }^{2)}$ \\ ${ }^{1)}$ Clinics for Cattle and ${ }^{2)}$ Horses, University of Veterinary Medicine, 30173 Hanover, Germany and ${ }^{3)}$ Graduate School of \\ Animal and Food Hygiene, Obihiro University of Agriculture and Veterinary Medicine, Obihiro 080-8555, Japan
}

\begin{abstract}
The goal of this study was to investigate for the first time a possible association between plasma concentrations of testosterone and total estrogen and testicular blood flow in the stallion. Correlations between these variables were calculated before and after administration of human chorionic gonadotropin (hCG). Eight mature warmblood stallions received 5,000 IU hCG intravenously, and four stallions received solvent only. Testicular blood flow in the left and right testicular arteries was assessed using colour Doppler sonography by measuring blood flow volume (BFV) and pulsatility index (PI) immediately before (time 0) and 1, 3, 6, 12, 24, 72,120 and $168 \mathrm{~h}$ after hCG administration. EDTA blood samples were collected after each examination from a jugular vein to measure plasma testosterone and total estrogen concentrations. After treatment, the BFV increased and was elevated at $1 \mathrm{~h}$ and between 12 and $24 \mathrm{~h}$. The profile of the PI was contrary to that of the BFV throughout the study period. Following hCG, there was a biphasic increase in testosterone concentration with maxima between 1 and $3 \mathrm{~h}$ and between 24 and $72 \mathrm{~h}$, and there was a monophasic increase in the total estrogen concentration with a maximum between 6 and $24 \mathrm{~h}$. At time 0 , the total estrogen concentration correlated significantly with BFV $(r=0.90 ; \mathrm{P}<0.05)$ but the testosterone concentration did not $(\mathrm{P}>0.05)$. The testosterone and total estrogen concentrations did not correlate with PI $(\mathrm{P}>0.05)$. The total estrogen concentration, but not testosterone, correlated well with BFV after injection of $\mathrm{hCG}(\mathrm{P}<0.05)$. The results of this study indicated that the testicular blood flow volume of the stallion may be regualted by estrogens, but additional studies are necessary to investigate whether there is a causal relationship.
\end{abstract}

Key words: Estrogen, Human chorionic gonadotropin (hCG), Stallion, Testicular blood flow, Testosterone

(J. Reprod. Dev. 54: 335-339, 2008)

$\mathbf{T}$ he testes are the site of production of spermatozoa as well as the male sex hormone, testosterone, and constitute a tissue of very high metabolic activity. Testicular tissue is very sensitive to disruption of its nutritive supply, which is primarily via the hematogenous route. Several investigations in humans [1-4] and rats [5, 6] have demonstrated an association between testicular blood flow and sperm quality. In addition to local mediators, hormones appear to be involved in regulation of testicular blood flow [6]. Receptors for LH and a transendothelial transport mechanism for human chorionic gonadotropin (hCG) have been found in the testicular microvasculature of rats [7]. Administration of hCG results in an increase in testosterone concentration and testicular blood flow in laboratory rodents $[8,9]$. An increase in plasma testosterone concentration after administration of hCG also occurs in stallions [10-12]. Estrogens, which have a marked vasodilatory effect [13] and can be converted from testosterone [10, 12], also increase after hCG treatment.

The goal of the present study was to investigate the possible association between plasma concentrations of testosterone and total estrogen and testicular blood flow in the stallion using Doppler sonography. Correlations between these variables were calculated

Accepted for publication: June 6, 2008

Published online in J-STAGE: July 30, 2008

Correspondence: $\mathrm{H}$. Bollwein

(e-mail: Heinrich.Bollwein@tiho-hannover.de) before and after administration of hCG.

\section{Material and Methods}

Animals and experimental design

Twelve clinically healthy Hannovarian stallions from the national state stud of Lower Saxony in Celle were used during July and August 2003. The stallions were kept in individual box stalls, fed hay and oats and were provided with free access to water. The stallions had been used for breeding mares by artificial insemination during the preceding season but were used only sporadically for semen collection during the present trials. All of the stallions had normal fertility. The stallions were divided into 2 groups with a similar age composition. The treated group consisted of 8 stallions with a mean age of $12.6 \pm 1.6$ years (SE; range: 7 to 20 years) and the control group consisted of 4 stallions with a mean age of $12.5 \pm 1.3$ years (range: 10 to 16 years). Doppler sonographic examination of both testicular arteries was carried out immediately before (time 0 ) and 1, 3, 6, 12, 24, 72, 120 and $168 \mathrm{~h}$ after intravenous injection of 5,000 IU hCG (Ovogest ${ }^{\circledR}$ 5,000; Intervet, Unterschleissheim, Germany) in the treated group and the same volume of solvent only ( $5 \mathrm{ml}$ ) in the control group. After each sonographic examination, a venous blood sample was collected. Plasma was separated and stored at $-20 \mathrm{C}$ until analysis of testosterone and total estrogen concentrations. 


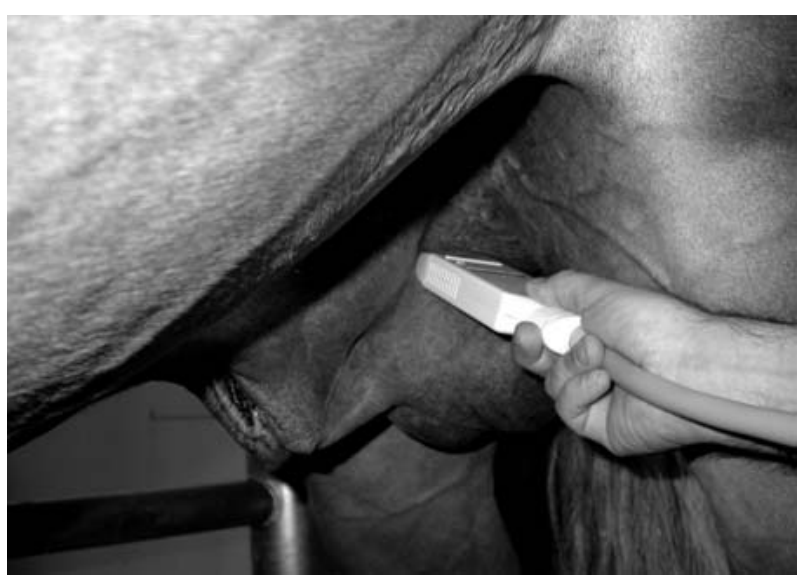

Fig. 1. Positioning of the ultrasound probe for determination of testicular blood flow.

\section{Blood collection and hormone analysis}

After each Doppler sonographic examination, a blood sample was collected from a jugular vein into an evacuated EDTA-tube. The samples were place on ice for no longer than 1 hour and then centrifuged at $4 \mathrm{C}$ and 2,000 $\mathrm{g}$ for $15 \mathrm{~min}$. The plasma was harvested and stored at $-20 \mathrm{C}$. A commercial ELISA (DRG Instruments, Marburg, Germany) was used to determine plasma testosterone concentrations but the test kit was modified such that testosterone (Sigma T5411; Sigma-Aldrich Chemicals, St. Louis, MO, USA) was used to create a standard curve. Plasma from a gelding with and without the addition of $10.0 \mathrm{ng}$ of testosterone was used as a control. The plasma concentration of total estrogen was determined using an ELISA [antibody: 1,3,5 (10)-estradiol3,17 $\beta$-diol-17-HS-BSA code 2/3Whst; marker: 1,3,5(10)-estradien-3,17 $\beta$-diol-17HS_HRP] as described elsewhere $[14,15]$.

\section{Colour doppler sonography}

The sonographic examinations of the left and right testicular arteries were conducted in a quiet area of the barn. An assistant held the stallion by a lead chain and halter; the stallions were not placed in examination stocks. An Eccocee CX sonographic system with a $7.0 \mathrm{MHz}$ microconvex probe (Toshiba, Tokyo, Japan) was used for all examinations. The left and right testes were examined from the left and right side, respectively. During the examination, the testis was held manually but no traction was applied. The probe was placed on the lateral side of the spermatic cord at a level halfway between the testis and the external inguinal ring (Fig. 1) such that the coiled part of the testicular artery could be imaged. The Doppler gate was then directed towards a section of the testicular artery at an angle of between 20 and $60^{\circ}$ in the direction of blood flow with the high-pass filter in PW mode set at $50 \mathrm{~Hz}$. The flowvelocity waveforms were recorded on videotape and analyzed on a Macintosh computer using an image analysis program (NIHImage, version 1.60; US National Institute of Health, 1996). The angle $\alpha$ between the Doppler beam and the direction of blood flow, peak systolic frequency shift (PSF), minimum diastolic frequency shift (MF) and time-averaged maximum frequency shift (TAMF) were determined for one cardiac cycle. For measurement of TAMF, an envelope was placed around the Doppler wave, and the area under the curve was calculated. Multiplication of TAMF by $\cos \alpha$ yielded the time-averaged maximum blood flow velocity (TAMV). Three images acquired in B-mode of a cross-section of the testicular artery were used to calculate the mean of this variable (A). The blood flow volume (BFV) per unit of time was calculated by multiplying A by TAMV. As a measure of blood flow resistance, the pulsatility index (PI) was determined for 2 consecutive blood flow curves using the formula below, and the mean was calculated.

$$
\text { Pulsatility index }=\frac{(\mathrm{PSF}-\mathrm{MF})}{\mathrm{TAMF}}
$$

\section{Statistical analysis}

Statistical analysis was carried out using the StatView 5.0 software package (SAS Institute, Cary, NC, USA, 1998). The Kolmogorov-Smirnoff test revealed that the data were not sampled from a population with a normal distribution. Thus, medians, mean absolute deviations (MAD) and 10-, 25-, 75- and 90\%-quantiles are shown in the figures. Furthermore, Spearman non- parametric correlations were calculated. The Wilcoxon signed rank test was used for within-group comparisons of hormone values at different sampling times.

\section{Results}

There were no significant differences between the left and right testicular arteries with respect to BFV and PI ( $P>0.05)$, but there were correlations between the left and right testicular arteries for these variables (BFV, $r=0.50 ; \mathrm{PI}, \mathrm{r}=0.51 ; \mathrm{P}<0.05$ ). Thus, the means of the left and right arteries were used for further analysis of these variables.

\section{Hormones}

The concentration of testosterone of the stallions in the control group did not change during the study $(\mathrm{P}<0.05$; Table 1$)$. In contrast, the concentration of testosterone in the treated group increased within $1 \mathrm{~h}$ of hCG administration and remained elevated for $3 \mathrm{~h}(\mathrm{P}<0.05)$. Thereafter, the concentration of testosterone decreased transiently $(\mathrm{P}<0.05)$, but later increased to reach maximum levels between 24 and $72 \mathrm{~h}$ after treatment $(\mathrm{P}<0.05)$. After the second peak, the concentration of testosterone decreased, but was twice the baseline value $168 \mathrm{~h}$ post hCG $(\mathrm{P}<0.05)$.

There was no change in the concentration of total estrogen in the control group ( $\mathrm{P}>0.05$; Table 1$)$. In the treated group, the concentration of total estrogen remained at the baseline value until $3 \mathrm{~h}$ after administration of hCG but at $6 \mathrm{~h}$ after administration, it was increased $(\mathrm{P}<0.05)$. The concentration of total estrogen remained unchanged between 6 and $24 \mathrm{~h}$ post hCG, but then decreased continually and was $59 \%$ of the baseline value at $168 \mathrm{~h}$ post hCG $(\mathrm{P}<0.05)$.

\section{Testicular blood flow}

The BFV of the control group did not change during the study 
Table 1. Plasma testosterone and total estrogen concentrations in stallions before and after administration of hCG (treatment group, $\mathrm{n}=8$ ) or solvent (controls, $\mathrm{n}=4$ )

\begin{tabular}{ccccc}
\hline \multirow{2}{*}{$\begin{array}{l}\text { Time }(\mathrm{h}) \text { after } \\
\text { injection }\end{array}$} & \multicolumn{2}{c}{ Testosterone $(\mathrm{ng} / \mathrm{ml})$} & \multicolumn{2}{c}{ Total estrogen (pmol/ml) } \\
& Control group & Treated group & Control group & Treated group \\
\hline 0 & $0.30 \pm 0.00$ & $0.53 \pm 0.14^{\mathrm{a}}$ & $294 \pm 89$ & $197 \pm 41^{\mathrm{a}}$ \\
1 & $0.35 \pm 0.05$ & $1.35 \pm 0.35^{\mathrm{b}, \mathrm{c}}$ & $278 \pm 107$ & $210 \pm 75^{\mathrm{a}}$ \\
3 & $0.65 \pm 0.25$ & $2.80 \pm 0.40^{\mathrm{b}}$ & $288 \pm 107$ & $252 \pm 54^{\mathrm{a}}$ \\
6 & $1.35 \pm 0.30$ & $1.75 \pm 0.25^{\mathrm{c}}$ & $379 \pm 19$ & $321 \pm 91^{\mathrm{b}}$ \\
12 & $1.20 \pm 0.15$ & $1.90 \pm 0.60^{\mathrm{c}}$ & $374 \pm 77$ & $351 \pm 66^{\mathrm{b}}$ \\
24 & $0.70 \pm 0.15$ & $2.15 \pm 0.40^{\mathrm{b}, \mathrm{c}, \mathrm{d}}$ & $315 \pm 90$ & $353 \pm 72^{\mathrm{b}}$ \\
72 & $0.60 \pm 0.10$ & $2.80 \pm 1.05^{\mathrm{d}}$ & $275 \pm 30$ & $185 \pm 37^{\mathrm{a}}$ \\
120 & $0.65 \pm 0.30$ & $1.15 \pm 0.35^{\mathrm{c}}$ & $277 \pm 27$ & $154 \pm 51^{\mathrm{a}}$ \\
168 & $0.95 \pm 0.45$ & $1.05 \pm 0.30^{\mathrm{c}}$ & $350 \pm 140$ & $116 \pm 45^{\mathrm{c}}$ \\
\hline
\end{tabular}

The medians and mean absolute deviations (MAD) of both testicular arteries are given.

A, b, c, dValues with different superscripts within the same column are significantly different $(\mathrm{P}<0.05)$

Table 2. Pulsatility index and blood flow volume of the testicular arteries in stallions before and after administration of hCG (treatment group, $\mathrm{n}=8$ ) or solvent (controls, $\mathrm{n}=4$ )

\begin{tabular}{ccccc}
\hline \multirow{2}{*}{$\begin{array}{c}\text { Time (h) after } \\
\text { injection }\end{array}$} & \multicolumn{2}{c}{ BFV (ml/min) } & PI \\
& Control group & Treated group & Control group & Treated group \\
\hline 0 & $36.7 \pm 6.5$ & $28.5 \pm 5.5^{\mathrm{a}}$ & $1.81 \pm 0.04$ & $2.46 \pm 0.68^{\mathrm{a}}$ \\
1 & $37.9 \pm 11.7$ & $32.0 \pm 6.3^{\mathrm{b}}$ & $1.96 \pm 0.11$ & $1.91 \pm 0.39^{\mathrm{b}}$ \\
3 & $44.1 \pm 11.7$ & $29.1 \pm 5.1^{\mathrm{a}, \mathrm{b}}$ & $2.08 \pm 0.14$ & $2.16 \pm 0.28^{\mathrm{a}, \mathrm{b}}$ \\
6 & $34.2 \pm 1.5$ & $28.2 \pm 7.2^{\mathrm{a}, \mathrm{b}}$ & $1.91 \pm 0.07$ & $2.12 \pm 0.38^{\mathrm{a}, \mathrm{b}}$ \\
12 & $36.5 \pm 7.0$ & $31.2 \pm 7.6^{\mathrm{a}, \mathrm{b}}$ & $1.88 \pm 0.22$ & $2.35 \pm 0.38^{\mathrm{a}}$ \\
24 & $37.2 \pm 7.0$ & $34.4 \pm 9.2^{\mathrm{b}}$ & $1.86 \pm 0.08$ & $1.69 \pm 0.32^{\mathrm{b}}$ \\
72 & $34.0 \pm 2.0$ & $23.8 \pm 3.7^{\mathrm{a}}$ & $1.82 \pm 0.10$ & $2.34 \pm 0.50^{\mathrm{a}}$ \\
120 & $27.4 \pm 6.6$ & $23.9 \pm 4.1^{\mathrm{a}, \mathrm{b}}$ & $1.79 \pm 0.18$ & $2.32 \pm 0.82^{\mathrm{a}}$ \\
168 & $27.7 \pm 1.6$ & $18.3 \pm 3.8^{\mathrm{c}}$ & $2.16 \pm 0.23$ & $2.26 \pm 0.35^{\mathrm{a}, \mathrm{b}}$ \\
\hline
\end{tabular}

The medians and mean absolute deviations (MAD) of both testicular arteries are given.

A, b, c, dValues with different superscripts within the same column are significantly different $(\mathrm{P}<0.05)$

(Table 2; $\mathrm{P}>0.05$ ). In the treated group, there was a short-lived increase in BFV within the first hour $(\mathrm{P}<0.05)$ that was followed by a slight decrease $(\mathrm{P}<0.07)$. This was followed by another increase that led to values 12 to $24 \mathrm{~h}$ after treatment that were greater than the baseline value $(\mathrm{P}<0.05)$. The BFV continued to decrease in the following days and was lower than the baseline value at $168 \mathrm{~h}$ after hCG administration $(\mathrm{P}<0.05)$.

The profile of the PI was contrary to that of the BFV throughout the study. The PI decreased to below the baseline value by one hour after hCG administration $(\mathrm{P}<0.05)$ but then increased until 12 $\mathrm{h}$ after treatment. The PI was below the baseline value at $24 \mathrm{~h}$ post hCG $(\mathrm{P}<0.05)$ and equal to the baseline value at $72 \mathrm{~h}$ post hCG. It did not change thereafter $(\mathrm{P}>0.05)$ until the end of the study.

\section{Correlation between the changes in testicular blood flow and plasma steroid hormone concentrations}

At time 0 , the plasma total estrogen concentration was correlated with BFV ( $\mathrm{r}=0.90 ; \mathrm{P}<0.05)$, but the plasma testosterone concentration was not $(\mathrm{P}>0.05)$. There were no correlations $(\mathrm{P}>0.05)$ between plasma testosterone or plasma total estrogen and PI.

For comparison of the changes in testicular blood flow with the changes in plasma steroid hormone concentrations after injection of hCG, the means from time 0 were calculated for each variable. These means were then taken as reference values and arbitrarily set as $100 \%$ (Figs. 2 and 3).

There was a parallel increase in the relative changes of plasma testosterone concentration and BFV and a decrease in the relative changes of PI during the first hour after treatment (Figs. 2 and 3). Between hours 1 and 3, the plasma testosterone concentration remained at elevated levels, whereas the BFV returned to pretreatment values. After $24 \mathrm{~h}$, both the plasma testosterone concentration and BFV reached maximum levels again and the PI reached minimum values. While the BFV and PI had already returned to pretreatment values by $72 \mathrm{~h}$ after treatment, the testosterone concentrations remained at maximum levels at this time. Thereafter, PI did not change, while the BFV and plasma testosterone concentration decreased to a value below and greater than the pretreatment value, respectively.

Starting at $3 \mathrm{~h}$ and lasting until the end of the study period, the profile of the relative changes in BFV resembled that of the total estrogen concentration in contrast to the relative alterations of PI. 


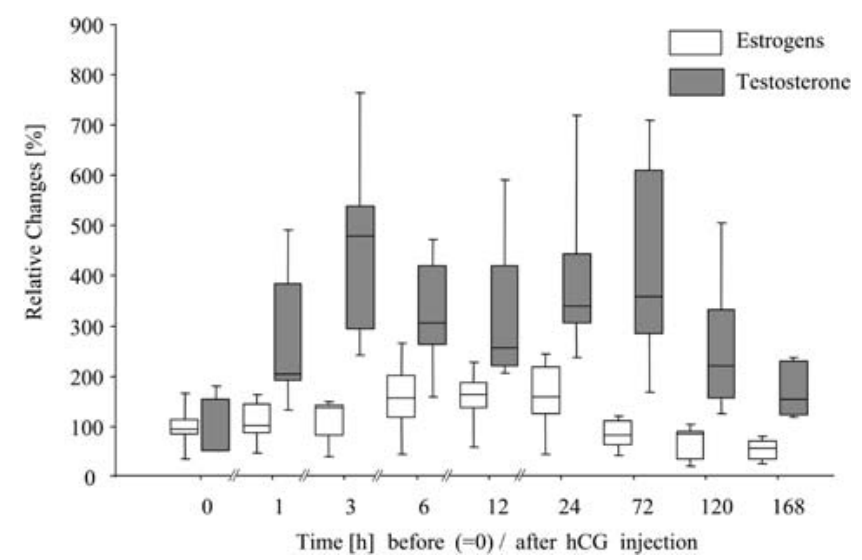

Fig. 2. Relative changes in the plasma testosterone and total estrogen concentrations in stallions $(\mathrm{n}=8)$ before and after intravenous administration of 5,000 IU hCG. The means from time 0 were calculated for each variable and arbitrarily set as $100 \%$. The horizontal lines of the box-and-whisker plots represent, from bottom to top, the $10^{\text {th }}, 25^{\text {th }}, 75^{\text {th }}$ and $90^{\text {th }}$ percentiles.

\section{Discussion}

In the present study, administration of hCG to stallions led to an increase in testicular blood flow similar to that seen in rats $[8,9,16$, 17]. We observed a biphasic undulating pattern in testicular blood flow variables; the blood flow volume peaked at 1 and $24 \mathrm{~h}$. At the same time points, the pulsatility index exhibited minimum values. Whereas in rats the blood flow volume increases two- to three-fold in response to hCG, it increased by only about $20 \%$ of pretreatment levels in the present study. However, in relative terms, the hCG doses used in rats (50 to $200 \mathrm{IU}$ ) were much larger than those used in the horses in the present study.

The increase in testicular blood flow after hCG has been associated with an increase in the testosterone concentration [8, 17-19]; this association was also observed in the present study. The increase in plasma testosterone concentration was biphasic, and the maximum concentrations were observed at 1 to $3 \mathrm{~h}$ and at 24 to 72 $\mathrm{h}$ as described elsewhere [10, 20-23]; however, the peak concentrations in the present study were lower than those in other studies [10, 11, 21-23]. A possible explanation for this is that other studies used larger doses $10,000 \mathrm{IU}$ in full-sized horses [10, 12, 23] and 6,000 IU in ponies $[11,21,22]$. However, comparison of the profiles of the relative changes in the testosterone concentration and testicular blood flow showed that there was a relatively short-lived increase during the first hour in the latter variable whereas the former continued increasing until $3 \mathrm{~h}$ after treatment. This contradicts the notion that testosterone controls testicular blood flow [24]. Because Leydig cells are capable of estrogen synthesis via aromatization of androgens [12] and because estrogens have a strong vasodilatory effect [13], an important objective of this study was to investigate the effect of experimental hCG administration on blood estrogen concentrations and the possible association between

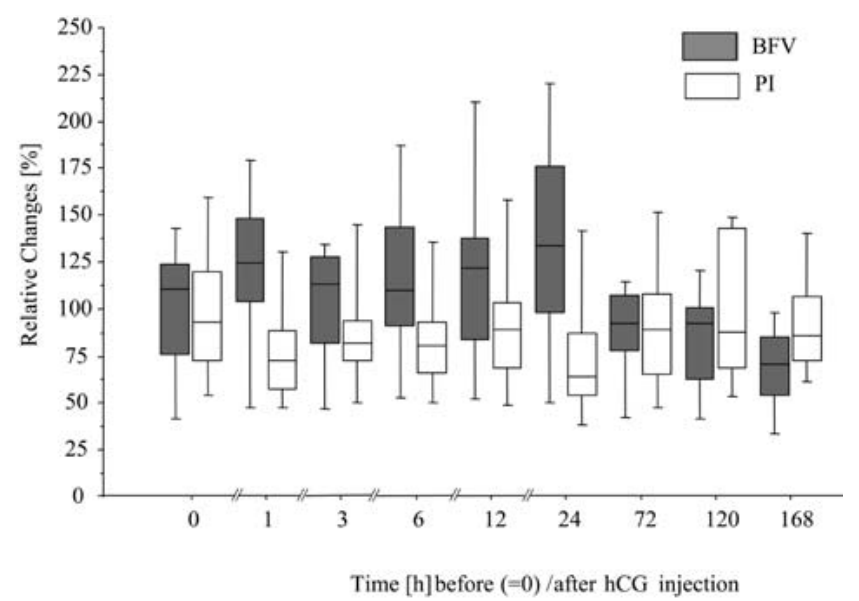

Fig. 3. Relative changes in blood flow volume and pulsatility index in stallions (=8) before and after intravenous administration of 5,000 IU hCG. The means from time 0 were calculated for each variable and arbitrarily set as $100 \%$. The horizontal lines of the box-and-whisker plots represent, from bottom to top, the $10^{\text {th }}$, $25^{\text {th }}, 75^{\text {th }}$ and $90^{\text {th }}$ percentiles.

changes in estrogen concentrations and testicular blood flow. In agreement with previous studies [10, 12, 25], administration of hCG was associated with an increase in total estrogen concentration; however, not within $1 \mathrm{~h}$ of hCG injection as described in one report [10]. The increase was delayed by about $6 \mathrm{~h}$. The estrogen concentration remained elevated until $24 \mathrm{~h}$ and decreased to below the pretreatment concentration thereafter. Furthermore, there was a lag between the changes in the testosterone and total estrogen concentrations. This observation is consistent with transformation of testosterone into estrogens as proposed by some researchers [10, 12]. In fact, the pattern of relative changes in the total estrogen concentration resembled that of testicular blood flow, supporting the notion that the changes in testicular blood flow after hCG are caused primarily by changes in the total estrogen concentration.

A strong correlation between the total estrogen concentration and testicular blood flow also occurred in the stallions of the control group. These relationships indicate that estrogens may play a physiologic role in testicular perfusion; however, verification of this hypothesis requires further studies with exogenous administation of estrogens or inhibition of estrogens in stallions. We do not think that the early increase in testicular blood flow during the first hour after hCG was caused by estrogens, which by that time had not yet increased. Rather, the increase may have been a direct effect of hCG as previously described in the rat [6, 26, 27]; symptoms resembling inflammation and inhibition of vasomotion with relaxation of precapillary sphincters occurred $1 \mathrm{~h}$ after injection of hCG.

In summary, we demonstrated the first evidence that the testicular blood flow of stallions is stimulated by hCG administration. This increase may be regulated by the vasodialting action of estrogens but further experimental study is required to confirm this hypothesis. 


\section{References}

1. Battaglia C, Giulini S, Regnani G, Di Girolamo R, Paganelli S, Facchinetti F, Volpe A. Seminal plasma nitrite/nitrate and intratesticular Doppler flow in fertile and infertile subjects. Hum Reprod 2000; 15: 2554-2558.

2. Battaglia C, Giulini S, Regnani G, Madgar I, Facchinetti F, Volpe A. Intratesticular Doppler flow, seminal plasma nitrites/nitrates, and nonobstructive sperm extraction from patients with obstructive and nonobstructive azoospermia. Fertil Steril 2001; 75 : 1088-1094.

3. Biagiotti G, Cavallini G, Modenini F, Vitali G, Gianaroli L. Spermatogenesis and spectral echo-colour Doppler traces from the main testicular artery. BJU Int 2002; 90: 903-908.

4. Tarhan S, Gumus B, Gunduz I, Ayyildiz V, Goktan C. Effect of varicocele on testicular artery blood flow in men-color Doppler investigation. Scand J Urol Nephrol 2003; 37: $38-42$.

5. Bergh A, Collin O, Lissbrant E. Effects of acute graded reductions in testicular blood flow on testicular morphology in the adult rat. Biol Reprod 2001; 64: 13-20.

6. Bergh A, Damber JE. Vascular controls in testicular physiology. In: de Kretser DM (ed.), Molocular Biology of the Male Reproductive System. Academic Press, New York, 1993; 439-468.

7. Ghinea N, Hai M, Groyer-Picard M, Milgrom E. How protein hormones reach their target cells. Receptor-mediated transcytosis of hCG through endothelial cells. J Cell Biol 1994; 125: 87-97.

8. Damber JE, Bergh A, Daehlin L. Testicular blood flow, vascular permeability, and testosterone production after stimulation of unilaterally cryptorchid adult rats with human chorionic gonadotropin. Endocrinology 1985; 117: 1906-1913.

9. Setchell BP, Sharpe RM. Effect of injected human chorionic gonadotrophin on capillary permeability, extracellular fluid volume and the flow of lymph and blood in the testes of rats. J Endocrinol 1981; 91: 245-254

10. Roser JF. Endocrine profiles in fertile, subfertile, and infertile stallions: testicular response to human chorionic gonadotropin in infertile stallions. Biol Reprod Mono 1995; $1: 661-669$

11. Setchell BP, Cox JE. Secretion of free and conjugated steroids by the horse testis into lymph and venous blood. J Reprod Fertil Suppl 1982; 32: 123-127.

12. Zwain I, Gaillard JL, Dintinger T, Silberzahn P. Down-regulation of testicular aromatization in the horse. Biol Reprod 1989; 40: 503-510.
13. Rosenfeld CR, Roy T, Cox BE. Mechanisms modulating estrogen-induced uterine vasodilation. Vascul Pharmacol 2002; 38: 115-125.

14. Meyer HH, Rohleder M, Streich WJ, Goltenboth R, Ochs A. Sex steroid profiles and ovarian activities of the female panda Yan Yan in the Berlin Zoo. Berl Munch Tierarzt Wochenschr 1997; 110: 143-147.

15. Meyer HHD. Enzymimmunulogische Meßverfahren zur Hormonanalytik. Ferdinand Enke Verlag, Stuttgart, 1989 (in German).

16. Damber JE, Bergh A, Widmark A. Testicular blood flow and microcirculation in rats after treatment with ethane dimethyl sulfonate. Biol Reprod 1987; 37: 1291-1296.

17. Damber JE, Selstam G, Wang J. Inhibitory effect of estradiol-17 beta on human chorionic gonadotropin-induced increment of testicular blood flow and plasma testosterone concentration in rats. Biol Reprod 1981; 25: 555-559.

18. Wang J, Galil KA, Setchell BP. Changes in testicular blood flow and testosterone production during aspermatogenesis after irradiation. J Endocrinol 1983; 98: 35-46.

19. Wang JM, Gu CH, Qian ZM, Jing GW. Effect of gossypol on testicular blood flow and testosterone production in rats. J Reprod Fertil 1984; 71: 127-133.

20. Amann RP, Ganjam VK. Effects of hemicastration or hCG-treatment on steroids in testicular vein and jugular vein blood of stallions. J Androl 1981; 3: 132-139.

21. Cox JE, Williams JH, Rowe PH, Smith JA. Testosterone in normal, cryptorchid and castrated male horses. Equine Vet J 1973; 5: 85-90.

22. Cox JE, Redhead PH. Prolonged effect of a single injection of human chorionic gonadotrophin on plasma testosterone and oestrone sulphate concentrations in mature stallions. Equine Vet J 1990; 22: 36-38.

23. Silberzahn P, Zwain I, Guerin P, Benoit E, Jouany JM, Bonnaire Y. Testosterone response to human chorionic gonadotropin injection in the stallion. Equine Vet J 1988, 20: 61-63.

24. Damber JE, Bergh A. Testicular microcirculation-a forgotten essential in andrology? Int J Androl 1992; 15: 285-292.

25. Silberzahn P, Pouret EJ, Zwain I. Androgen and oestrogen response to a single injec tion of hCG in cryptorchid horses. Equine Vet J 1989; 21: 126-129.

26. Bergh A, Damber JE. HCG/LH-induced changes in testicular blood flow, microcirculation and vascular permeability in adult rats. In: Armstrong DT, Friesch HG (eds.) Endoncrinology and Physiology of Reproduction. Plenum Pub, New York, 1987; 243259

27. Damber JE, Bergh A, Fagrell B, Lindahl O, Rooth P. Testicular microcirculation in the rat studied by videophotometric capillaroscopy, fluorescence microscopy and laser Doppler flowmetry. Acta Physiol Scand 1986; 126: 371-376. 